\title{
Guillain-Barré syndrome: looking back... and forward
}

\author{
Richard A C Hughes
}

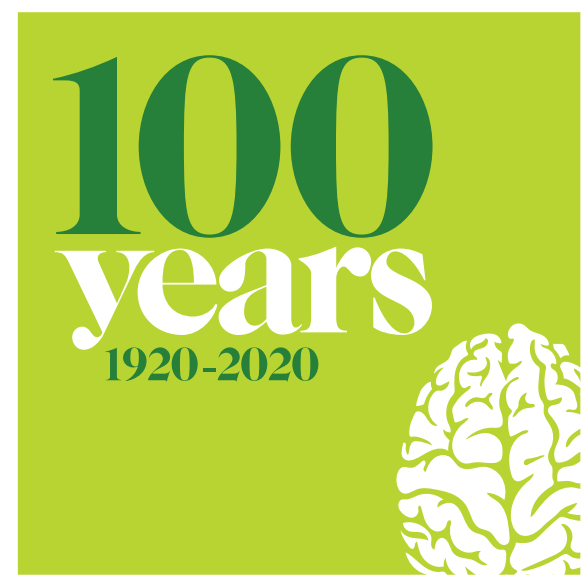

This editorial comments on a large prospective study of GBS in which a second course of intravenous immunoglobulin was unhelpful

In 1988 , in the first large-scale prospective study of Guillain-Barré syndrome (GBS), John Winer and colleagues collected and followed 100 patients from the London area. ${ }^{1}$ A year later, $20 \%$ of the patients were still unable to walk, and an additional 13\% had died, 10\% directly from the disease. The series was probably biased towards more severely affected patients. At that time only supportive treatment was available, plasma exchange was rarely used and intravenous immunoglobulin (IVIg) never. There have been many subsequent prospective studies of GBS but all have now been trumped by the International GBS Outcome Study (IGOS) which has collected more than 1800 patients. ${ }^{2}$ In an analysis of the first 1000 included patients, $8 \%$ were unable to walk and $7 \%$ had died after a year, with the prognosis being much worse in Bangladesh than in Europe/the Americas and the rest of Asia. ${ }^{3}$ It is likely that this study was also biased towards more severe disease as most patients were collected from large referral hospitals: this was confirmed in Denmark where the average severity was less in the population as a whole than in those captured by IGOS. ${ }^{4}$ In the series of Winer and colleagues, factors which

Correspondence to Professor Richard A C Hughes, Department of Neuromuscular Diseases, UCL Queen Square Institute of Neurology, London WC1N 3BG, UK; rhughes11@btinternet.com predicted a worse prognosis were rapidity of onset, need for ventilation, older age and small distally evoked compound muscle action potentials. ${ }^{1}$ A Dutch study of 397 patients identified older age, more severe weakness at presentation and a recent history of diarrhoea as the most important prognostic factors and allowed the construction of the modified Erasmus GBS Outcome Score (mEGOS) which predicted the outcome in a further cohort of 158 patients with reasonable accuracy. ${ }^{5}$ Analysis of the IGOS data should further refine this prognostic model and allow its generalisation to international populations.

The Winer and colleagues study also showed for the first time that serological evidence of recent Campylobacter jejuni and cytomegalovirus infection was more common than in hospital controls. ${ }^{6} \mathrm{C}$. jejuni and cytomegalovirus have now been repeatedly confirmed as precipitants. Epstein-Barr virus, hepatitis E, Mycoplasma pneumoniae, Influenza A, Haemophilus influenzae and, recently, Zika virus have been added as significant antecedent events. ${ }^{78}$ Interrogation of the IGOS biobank for differences in precipitants in different regions might help explain differences in the phenotype of the illness in different countries. How so many different precipitants cause an apparently similar clinical picture still defies explanation: subsequent studies have shown that GBS is a heterogeneous syndrome with different clinical patterns and different underlying pathologies.

Efforts to identify immune responses which might explain this inflammatory and presumed autoimmune neuropathy were even more frustrating in 1998 than now. Winer and colleagues found complement fixing antibodies to unidentified peripheral nerve antigens in only $7 \%$ of patients. ${ }^{9}$ They did not test for antiganglioside antibodies but, in the same year, Ilyas and colleagues found these in 20\% of patients. ${ }^{10}$ In the next decade, Griffin and coworkers made the critical separation of GBS into three main pathological subtypes: acute inflammatory demyelinating polyradiculoneuropathy, acute motor axonal neuropathy and acute motor and sensory axonal neuropathy. ${ }^{11}$ The acute motor axonal neuropathy subtype is closely associated with antibodies to gangliosides, especially gangliosides GM1 and GD1a. Yuki has reproduced its pathological and neurophysiological features in rabbits by immunisation with gangliosides, and Willison has generated monoclonal antibodies to gangliosides which destroy terminal motor axons in vivo and ex vivo in mice. ${ }^{12}$ The search for antibodies which would explain the pathogenesis of the acute inflammatory demyelinating polyradiculoneuropathy form of GBS continues. The role of $\mathrm{T}$ cells is more difficult to investigate and is now largely ignored. However, the macrophageassociated demyelination in experimental autoimmune neuropathy, for which $\mathrm{T}$ cell responses to myelin protein antigens are responsible, is tantalisingly similar to that in acute inflammatory demyelinating polyradiculoneuropathy. ${ }^{13}{ }^{14}$ Furthermore, T cell responses to peripheral nerve myelin protein P0 cause spontaneous inflammatory neuropathy in genetically engineered immunodeficient mouse strains. ${ }^{15}$

In addition to investigating pathogenesis, a potential use of prospective studies is to test the efficacy of new treatment regimens. The standard treatment is a single course of IVIg. According to a Cochrane Review including 536 participants from five randomised controlled trials, IVIg was no less efficacious for GBS than plasma exchange. Furthermore, three studies including a total of 75 children suggested that IVIg significantly hastens recovery compared with supportive care. All these studies used a standard IVIg regimen of $2.0 \mathrm{~g} / \mathrm{kg}$, usually as five daily $0.4 \mathrm{~g} / \mathrm{kg}$ courses. ${ }^{16}$ In this issue, Verboon and colleagues ${ }^{2}$ have interrogated the IGOS database to provide much needed information about the efficacy of a second course of IVIg. They focused on patients who were predicted by their mEGOS 1 week after their first course to have a poor prognosis: $16 \%$ of the 239 patients with a predicted poor prognosis received two courses of IVIg despite the absence of evidence that a second course is beneficial. They then compared those who were treated with two 5-day courses of IVIg 
with those who received only the standard single course. The two-course patients were divided into two groups: 20 who received a second immunoglobulin course within 14 days after the first course and 18 who received it after 14 days. Against expectations, there was less improvement in disability after 4 weeks in both groups than in the 199 who received only one course. These results may have been confounded by factors which mEGOS does not include. In particular, patients selected for a second course were more likely to be worsening at the time the second course was given than patients who did not receive a second course at the equivalent time. Nevertheless, this result does make a major beneficial effect unlikely. Complications from a second immunoglobulin course were not reported in the Verboon and colleagues' study, but risks from venous and arterial thrombosis are likely to be greater with higher doses of IVIg. The definitive answer to the question of the efficacy of a second immunoglobulin dose for GBS will have to await the results of the randomised controlled trial recently completed in the Netherlands. ${ }^{17}$

No new treatments for GBS have emerged during the last 20 years and IGOS shows that death and residual disability are still not uncommon. Evidence has not yet been provided that the overall prognosis has improved with modern intensive care and the introduction of plasma exchange and IVIg. New treatments are needed but the rarity of the disease makes randomised controlled trials difficult. By providing a cohort for comparison, IGOS allows at least preliminary investigation of the efficacy of novel treatments, such as complement blockade ${ }^{18}$ and IgG depletion. ${ }^{19}$
Contributors RACH is the sole author of this article.

Funding The author has not declared a specific grant for this research from any funding agency in the public, commercial or not-for-profit sectors.

Competing interests $\mathrm{RACH}$ reports personal fees from LFB, UCB and Sanofi, outside the submitted work, and being a medical patron of GAIN, the British organisation which supports patients with GBS.

Patient consent for publication Not required.

Provenance and peer review Commissioned; internally peer reviewed.

(C) Author(s) (or their employer(s)) 2020. No commercial re-use. See rights and permissions. Published by BMJ.

\section{Check for updates}

To cite Hughes RAC. J Neurol Neurosurg Psychiatry 2020;91:111-112.

Received 20 November 2019

Accepted 8 December 2019

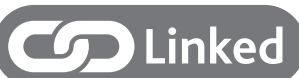

- http://dx.doi.org/10.1136/jnnp-2019-321496

J Neurol Neurosurg Psychiatry 2020;91:111-112. doi:10.1136/jnnp-2019-322361

ORCID iD

Richard A C Hughes http://orcid.org/0000-0001-52513797

\section{REFERENCES}

1 Winer JB, Hughes RA, Osmond C. A prospective study of acute idiopathic neuropathy. I. clinical features and their prognostic value. J Neurol Neurosurg Psychiatry 1988:51:605-12.

2 Jacobs BC, van den Berg B, Verboon C, et al. International Guillain-Barré syndrome outcome study: protocol of a prospective observational cohort study on clinical and biological predictors of disease course and outcome in Guillain-Barré syndrome. J Peripher Nerv Syst 2017;22:68-76.

3 Doets AY, Verboon C, van den Berg B, et al. Regional variation of Guillain-Barré syndrome. Brain 2018; 141:2866-77.
4 Al-Hakem H, Sindrup SH, Andersen H, et al. GuillainBarré syndrome in Denmark: a population-based study on epidemiology, diagnosis and clinical severity. J Neurol 2019;266:440-9.

5 Walgaard C, Lingsma HF, Ruts L, et al. Early recognition of poor prognosis in Guillain-Barre syndrome. Neurology 2011;76:968-75.

6 Winer JB, Hughes RA, Anderson MJ, et al. A prospective study of acute idiopathic neuropathy. II. antecedent events. J Neurol Neurosurg Psychiatry 1988;51:613-8.

7 Willison $\mathrm{HJ}$, Jacobs BC, van Doorn PA. Guillain-Barré syndrome. The Lancet 2016;388:717-27.

8 Parra B, Lizarazo J, Jiménez-Arango JA, et al. GuillainBarré syndrome associated with Zika virus infection in Colombia. N Engl J Med 2016;375:1513-23.

9 Winer JB, Gray IA, Gregson NA, et al. A prospective study of acute idiopathic neuropathy. III. immunological studies. J Neurol Neurosurg Psychiatry 1988:51:619-25.

10 Ilyas AA, Willison HJ, Quarles RH, et al. Serum antibodies to gangliosides in Guillain-Barré syndrome. Ann Neurol 1988;23:440-7.

11 Griffin JW, Li CY, Ho TW, et al. Guillain-Barré syndrome in northern China: the spectrum of neuropathological changes in clinically defined cases. Brain 1995;118:577-95.

12 Goodfellow JA, Willison HJ. Guillain-Barré syndrome: a century of progress. Nat Rev Neurol 2016;12:723-31.

13 Lampert PW. Mechanism of demyelination in experimental allergic neuritis. electron microscopic studies. Lab Invest 1969;20:127-38.

14 Prineas JW. Acute idiopathic polyneuritis. An electron microscope study. Lab Invest 1972;26:133-47.

15 Soliven B. Autoimmune neuropathies: insights from animal models. J Peripher Nerv Syst 2012;17:28-33.

16 Hughes RAC, Swan AV, van Doorn PA. Intravenous immunoglobulin for Guillain-Barré syndrome. Cochrane Database Syst Rev 2012:CD002063.

17 Verboon C, Berg Bvanden, Cornblath DR, et al. Second IVIg course in Guillain-Barré syndrome with poor prognosis: the non-randomised ISID study. J Neurol Neurosurg Psychiatry 2019:1-9.

18 A clinical study of ANX005 and IVIg in subjects with Guillain-Barré syndrome. Available: https://clinicaltrials. gov/ct2/show/NCT04035135

19 A study of Imlifidase in patients with Guillain-Barré syndrome. Available: https://clinicaltrials.gov/ct2/show/ NCT03943589 